\title{
231 STUDY ON RELEVANT EFFECTS OF AEROYOGA ON PHYSIOLOGICAL PARAMETERS OF YOUTH
}

Benu Gupta, ${ }^{1}$ Mukesh Agarwal, ${ }^{2}$ Sunita Arora ${ }^{3}{ }^{1}$ Department of Physical Education, Kirori Mal College, University of Delhi, Delhi, India; ${ }^{2}$ Department of Physical Education, Maharaja Agrasen College, University of Delhi, Delhi, India; ${ }^{3}$ Department of Physical Education, Lakshmibai College, University of Delhi, Delhi, India

10.1136/bjsm.2010.078725.231

The purpose was to study the relevant effects of new fitness regime aeroyoga on physiological parameters of the youth. The sample subjects were confined to the youth students ageing 16-21 years of Delhi and NCR. A total of 60 subjects were chosen randomly for the study. They were divided into three groups of 20 each. One group was treated with the regime of aerobics; the second was with yogasanas and the third with aeroyoga for fitness. The aeroyoga - a complete new fitness 
regime was developed and implemented on controlled and experimental group in comparison with yogasana and aerobic battery for the relevance. The physiological parameters were measured at three stages that is, at resting, pre-operational and post-operational. Also, the subjective assessment was done once in between the operation and after the completion of battery. Physiological measures considered were: Wt, Ht, $\mathrm{BMI}$, fat $\%$, hip-waist ratio, $\mathrm{HR}, \mathrm{MHR}, \mathrm{BMR}, \mathrm{VO}_{2}$ max and pulse rate. Analysis of variance - statistical technique was used to study the relevant effect of aeroyoga in comparison with aerobics and yogasana. The whole statistical work deals with study of independent and interaction effects as well as mean difference in $\mathrm{Wt}, \mathrm{Ht}, \mathrm{BMI}$, fat $\%$, hip-waist ratio, $\mathrm{HR}$, MHR, BMR, $\mathrm{VO}_{2}$ max, pulse rate and subjective assessment of aeroyoga, aerobics and yogasana battery on active and passive youth. The result revealed the significant difference in $\mathrm{Wt}, \mathrm{BMI}$, fat $\%$, hip-waist ratio, $\mathrm{HR}, \mathrm{BMR}, \mathrm{VO}_{2}$ max, pulse rate in youth going through aeroyoga, aerobics and yogasana. Whereas there was no significant difference found in $\mathrm{Ht}$ and MHR. The significant difference was found in subjective assessment.

\section{Conclusions}

The fitness battery of aeroyoga was found to delay the onset of fatigue in comparison to other fitness battery.

Aeroyoga was found to be more suitable fitness programme for the people irrespective of their physical and mental condition. Aeroyoga was found to produce maximum workout in minimum time frame when compared with other two fitness regime employed. 